Evaluation of a phosphate management protocol to achieve optimum serum phosphate levels in haemodialysis patients

Dawn Yokum ${ }^{1}$ BSc RD, Georgina Glass ${ }^{2}$ BPharm DipClinPharm MRPharmS, Ching Fun Cheung $^{3}$ BPharm MRPharmS, John Cunningham ${ }^{4}$ DM FRCP, Stanley Fan ${ }^{5}$ MBBChir MRCP, Angela M Madden ${ }^{6} \mathrm{PhD}$ RD

Renal Unit, Barts and the London NHS Trust, The Royal London Hospital, Whitechapel Road, London E1 1BB, UK

${ }^{1}$ Senior Renal Dietitian, Barts and the London NHS Trust and Department of Health and Human Sciences, London Metropolitan University; ${ }^{2}$ Senior Directorate Pharmacist Renal Services, Barts and the London NHS Trust; ${ }^{3}$ Antimicrobials Pharmacist, Bedford Hospital; ${ }^{4}$ Professor of Nephrology, University College London; ${ }^{5}$ Consultant Nephrologist, Barts and the London NHS Trust; ${ }^{6}$ Principal Lecturer in Dietetics, University of Hertfordshire.

Acknowledgement: This study was funded by a Multidisciplinary Health Service Research Award from the BLT NHS Trust and by an educational grant from Shire Pharmaceuticals Ltd.

Corresponding author: Dr Angela Madden, School of Health \& Emergency Professions, University of Hertfordshire, Hatfield, Hertfordshire AL10 9DB; telephone 01707 281385; fax 01707 281385; email a.madden@herts.ac.uk 


\title{
Evaluation of a phosphate management protocol to achieve optimum serum phosphate levels in haemodialysis patients
}

\begin{abstract}
Objective: To evaluate the effectiveness of a protocol designed to optimise serum phosphate levels in patients undergoing regular haemodialysis.

Design: Randomised, controlled trial.

Setting: Haemodialysis units at Barts and the London NHS Trust and satellite units.

Patients: Thirty-four clinically stable adults undergoing regular haemodialysis with a serum phosphate level $>1.8 \mathrm{mmol} / \mathrm{l}$ on at least one occasion within 4 months of starting the study. Intervention: Management of serum phosphate using a specially designed phosphate management protocol during a 4-month study period implemented by a renal dietitian and renal pharmacist compared to standard practice.
\end{abstract}

Main outcome measure: Change in serum phosphate levels in both groups after 4 months. Results: Patients managed using the phosphate management protocol had a significantly greater reduction in serum phosphate levels compared to patients receiving standard practice $(-0.22 \pm$ 0.67 vs $+0.19 \pm 0.32 \mathrm{mmol} / \mathrm{l}, \mathrm{P}=0.03)$.

Conclusion: The phosphate management protocol was effective and its implementation associated with significantly better serum phosphate control in patients undergoing regular haemodialysis.

Five key words: Haemodialysis; phosphate; protocol; pharmacist; dietitian. 


\section{Introduction}

Patients undergoing regular haemodialysis (HD) are at risk of complications associated with elevated serum phosphate levels which increasingly stimulate parathyroid gland production of parathyroid hormone (PTH) and proliferation and lead to accelerated bone resorption. ${ }^{1}$ Hyperphosphataemia and hypercalcaemia also increase the calcium-phosphate product, potentiating metastatic calcification in soft tissues. ${ }^{2}$ In addition, patients with elevated serum phosphate experience higher mortality and those with serum phosphate levels above $2.1 \mathrm{mmol} / 1$ have a significantly increased risk of dying during their first year of treatment. ${ }^{3}$

Standard thrice weekly HD is unable effectively to remove excess phosphate from the blood ${ }^{4}$ and, therefore, patients need to restrict their dietary intake of food rich in phosphate and to take oral phosphate binders to control both serum phosphate and PTH levels. ${ }^{5}$ Traditionally, patients are taught about the importance of both their diet and medication at the start of regular haemodialysis and this is reinforced as treatment continues. A number of studies have evaluated the efficacy of such teaching. ${ }^{6,7,8,9}$ Although some were unable to show a clinical benefit from teaching, ${ }^{7,8}$ others reported that higher levels of knowledge about diet and medication and receiving education from a dietitian were associated with lower serum phosphate levels. ${ }^{6,9}$

However, in spite of these interventions, hyperphosphataemia remains a problem for a substantial number of HD patients ${ }^{10}$ and there is a need to investigate standardised and reproducible protocols to facilitate the management of hyperphosphataemia. To this end, a phosphate management protocol was devised to enable renal dietitians and renal pharmacists to extend their traditional role in this area of practice under the auspices of a Patient Group Direction. ${ }^{11}$ The aim of this study was to evaluate the effectiveness of the protocol, designed to optimise serum phosphate levels in patients undergoing regular haemodialysis. 


\section{Methods}

\section{Subjects}

The subjects were recruited from adult outpatients with chronic renal failure undergoing regular haemodialysis (three times per week) and attending daytime sessions at Barts and the London (BLT) NHS Trust between June 2003 and September 2003. Inclusion criteria were age over 18 years, clinically stable, English speakers, mentally alert and elevated serum phosphate; patients with malignancy, gastrointestinal disorders including malabsorption, and planned surgery were excluded. Before entry into the study, serum phosphate levels were monitored for 4 months and patients with at least one value $>1.8 \mathrm{mmol} / \mathrm{l}$ during this period were invited to participate in the study. A total of thirty-four patients fitted the study criteria, agreed to participate and provided informed written consent. They were randomised into one of two study groups using a computer generated random number list:

i. Phosphate management protocol (PMP) group

ii. Standard practice (SP) group

At recruitment, the two groups were comparable in terms of age, sex, ethnic group, aetiology of kidney disease, length of time since commencing regular haemodialysis and body mass index (BMI) (Table 1). All study patients were reviewed and blood results monitored once per month for the 4-month duration of the study. At each monthly visit, all patients were seen individually by a renal dietitian who devised an individual care plan. The individual dietary advice was given after taking a diet history ${ }^{12}$ and comprised verbal advice supported by either a detailed low phosphate diet booklet providing a comprehensive list of high-phosphate foods to avoid and suitable alternatives, or a simplified handwritten diet action plan. The choice of written material was based on each patient's circumstances and their perceived ability to understand the instructions given. Patients were advised whilst they were undergoing dialysis. 


\section{Phosphate management protocol group}

In the PMP group, phosphate binder and alfacalcidol (vitamin D analogue) medication was adjusted using a specially designed phosphate management protocol. This was developed by the multi-disciplinary renal research team which included a renal consultant, dietitian and pharmacists. The protocol comprised two algorithms (Figure 1) that allowed the renal research pharmacists and renal research dietitian, working together, to change patients' medication as specified within the protocol without close supervision of a renal consultant. The protocol was

approved by the BLT Patient Group Direction Committee. ${ }^{11}$ The algorithms were used to inform changes to the dose and type of phosphate binder and the dose of alfacalcidol required to improve patients' serum phosphate, calcium and intact parathyroid hormone (iPTH) levels. Once per month, whilst the patients were undergoing dialysis, the renal research pharmacists explained the changes to their medication, counselled them about when to take them and adjustments in relation to the size of their meals, and provided a medication card. Once per month, the patients were also seen by the renal research dietitian.

\section{Standard practice group}

In the SP group, a senior doctor within the renal team reviewed the monthly blood results and the dose and type of phosphate binder and alfacalcidol during dialysis ward rounds or at an outpatient clinic. Once per month, the patients were also seen by a renal dietitian but were not seen by a pharmacist.

\section{Monitoring}

Routine blood samples were taken before dialysis within the first week of every month; serum was separated and frozen within 1 hour of blood collection. Serum phosphate and calcium concentrations were analysed using ultraviolet and colour photometric tests respectively ${ }^{13,14}$ and calcium-phosphate product $(\mathrm{Ca} \times \mathrm{P})$ was calculated. Serum calcium concentrations were adjusted 
with reference to serum albumin $($ corrected calcium $(\mathrm{mmol} / \mathrm{l})=$ measured calcium $(\mathrm{mmol} / \mathrm{l})+$ ([40 - albumin $(\mathrm{g} / \mathrm{l})] \times$ x 0.02). Serum iPTH and aluminium concentrations were measured at the beginning and end of the study by an automated chemiluminescent immunoassay and atomic absorption spectrophotometry respectively. ${ }^{15,16}$ Adequacy of haemodialysis was assessed by single-pool Kt/V calculated at recruitment and at the end of the study. ${ }^{17}$ Weight was recorded at the end of each dialysis session and using previously recorded height, BMI was calculated.

\section{Statistical analysis}

Power calculations indicated that a sample size of 17 patients in each group was required to detect a $15 \%$ reduction in serum phosphate levels $(80 \%$ power at a significance level of 0.05$)$ based on data from BLT haemodialysis patients in 2000. The distribution of variables was tested for normality using the Shapiro-Wilks' test (SAS 8.2, 2001, SAS Institute Inc, Cary, USA).

At baseline, comparisons were made between the two patient groups using unpaired tests for normally distributed data, (most biochemical / nutritional variables, age) and Mann Whitney U tests for data not normally distributed (iPTH, time on dialysis). The difference between the baseline and post-intervention results within each group were compared using paired t-tests and the Wilcoxon matched pairs test. The difference between the change from baseline to postintervention in the two groups was evaluated using unpaired $t$ tests and Mann Whitney U tests. Categorical data were compared using the chi-squared test (male to female ratio) and McNemar's test and Cochran's test for linear trend (number of patients achieving the K/DOQI targets ${ }^{18}$ ) (Systat 10.2, 2002, Systat Software UK Limited, Hounslow, UK).

The study protocol was approved by North East London Strategic Health Authority (NELSHA) Research Ethics Committee, reference number P/01/092. 


\section{Results}

Forty-two patients were recruited into the study and randomised to one of the two intervention groups; 34 of these received the interventions (Figure 2). Three patients did not complete the study and all of these were allocated to the PMP group; two were withdrawn in week 6 after developing complicated or confounding medical conditions (total parathyroidectomy for severe hyperparathyroidism and oropharyngeal squamous cell carcinoma requiring feeding via a gastrostomy) and the third died from septicaemia secondary to endocarditis in week 9. The data from these patients were included in the comparative analysis at recruitment (Table 1) but not in subsequent analyses.

Haemodialysis adequacy, as indicated by Kt/V, was comparable between the two groups at recruitment (PMP $1.30 \pm 0.25$ vs SP $1.32 \pm 0.17, \mathrm{P}=0.77)$ and at the end of the study (PMP $1.29 \pm$ 0.29 vs SP $1.43 \pm 0.20, \mathrm{P}=0.14$ ). Only one patient (SP group) had an elevated serum aluminium level before the intervention $(2.6 \mu \mathrm{mol} / 1)$. This responded to reducing her aluminium hydroxide dose. In all other patients, aluminium levels remained within acceptable limits throughout the study. BMI remained comparable in both groups throughout the study.

No statistically significant difference was observed in serum phosphate concentrations, corrected calcium, Ca x P or iPTH between the two groups at the start of the study (Table 2). However, after the study, a significant increase in serum phosphate was observed in the SP group whilst the PMP group showed a small, insignificant reduction. A comparison between the two groups over the study period showed a significantly greater improvement in serum phosphate levels in the PMP group compared to the patients receiving standard practice $(-0.22 \pm 0.67$ vs $0.19 \pm 0.32$ $\mathrm{mmol} / \mathrm{l}, \mathrm{P}=0.03$ ). Parallel differences in the change in Ca $\mathrm{x} \mathrm{P}$ product were observed between the two groups but there were no significant differences in the change in serum corrected calcium or iPTH levels (Table 2). 
The proportion of patients achieving the K/DOQI target for serum phosphate increased in the PMP but decreased in the SP group following the intervention period but the changes were not significant within groups (Table 3) or between groups (data not shown). Similarly, the proportion of patients meeting multiple K/DOQI targets increased in the PMP and decreased in the SP group but again these trends were not significant (Table 4).

Significantly more changes to the dose of individual phosphate binders were made in the PMP group than in the SP group (median [range] number of dose changes, PMP 5[1-7] vs SP 0 [0-3], $\mathrm{P}<0.001)$. The estimated time spent with patients in the PMP group each month by the pharmacists was 19 [8-25] minutes; patients in the SP group were not seen by the pharmacists.

Eight breaches of the study protocol occurred during the study relating to physicians changing binders between monthly reviews without reference to the protocol. On each occasion, when the breach was identified by the pharmacist, the blood levels were reviewed promptly against the protocol and an appropriate amendment made in compliance with the protocol. 


\section{Discussion}

The results from the current study show that use of a defined phosphate management protocol can lead to statistically significantly improved phosphate control over a 4-month period compared with standard therapy. Although a number of previous studies have evaluated the effects of single elements of managing hyperphosphataemia, including dietary counselling and education ${ }^{6,7,8,9,19,20}$ and pharmacotherapy, ${ }^{21,22}$ few have investigated an algorithm-based protocol for the management of hyperphosphataemia. Craven and Moreschi ${ }^{23}$ examined the effects of a protocol for administering intravenous calcitriol in haemodialysis patients and concluded that it decreased the incidence of elevated iPTH levels although no control group was included.

The use of dietary modification and pharmacotherapy is not without risk in this patient population. Dietary phosphate is associated with dietary protein and over-restriction may compromise nutritional adequacy ${ }^{24}$ and lead to undernutrition with its accompanying risk of increased mortality. ${ }^{25}$ No dietary data were collected during this study so the adequacy of patients' nutritional intake is unknown. However, BMI data suggest that the patients who participated in the study were likely to be well-nourished and no significant decrease in BMI was observed over the 4-month duration of either arms of the study. Calcium-containing phosphate binders are associated with progressive cardiovascular calcification ${ }^{26,27}$ whilst patients taking those containing aluminium have an increased risk of aluminium toxicity manifesting as encephalopathy and osteomalacia. ${ }^{28,29}$ In the present study, elevated serum aluminium levels were not a concern. Non-absorbable sevelamer is associated with fewer serious adverse effects, although gastrointestinal symptoms have been reported ${ }^{30,31}$ and it is one of the most expensive phosphate binders available. ${ }^{32}$ It has been speculated that by utilising a combination of phosphate binders in a systematic manner, the protocol might also reduce the risks associated with individual binders. ${ }^{22}$ A large prospective study would be required to address this. 
The total staff time required to deliver the phosphate management protocol compared with the standard treatment was not measured. Although, anecdotally no additional medical staff time was required with the PMP group, additional pharmacist and dietetic time was required. It could be argued that the additional staff time, rather than the protocol per se contributed to improved phosphate control. Future studies are needed to evaluate this and to explore the health economic implications of the protocol with regard to both staff time and prescribing costs.

The limitations of the study include the small number of patients studied. Although a statistically significant difference in the change of phosphate levels has been observed between the two groups, this small change is unlikely to have clinical significance. However, this could be explored in a future study by repeating the study in patients with more poorly controlled serum phosphate rather than in a population with a single serum phosphate level above $1.8 \mathrm{mmol} / \mathrm{l}$. It would be beneficial to also measure the residual renal function of patients, which was not done in the present study, in order to clarify their ability to control their serum phosphate. In future studies, the additional measurement of nutrient intake would allow the effect of dietary advice on phosphate intake to be directly evaluated as well as facilitating the examination of overall nutrient intake adequacy.

This study has shown that patients undergoing regular haemodialysis had significantly better serum phosphate control whilst managed with a protocol incorporating patient education, dietary counselling and pharmacotherapy than patients receiving standard management. A larger study is required to confirm whether the observed effects can be extended to other dialysis populations.

\section{Acknowledgements}

This study was funded by a Multidisciplinary Health Service Research Award from the BLT NHS Trust and by an educational grant from Shire Pharmaceuticals Ltd. The authors are 
grateful to the patients who participated in the study, the staff from the Renal Unit and the Departments of Nutrition and Dietetics, Pharmacy and Research and Development at BLT NHS Trust, especially Ifty Khan, Liz Paul and Fiona Warburton. 


\section{References}

1 Fan SLS, Cunningham J: How should hyperphosphataemia be managed in dialysis patients ? Semin Dial 15:321-324. 2002

2 Raggi P: Imaging of cardiovascular calcifications with electron beam tomography in haemodialysis patients. Am J Kidney Dis 37:S62-S65, 2001 (suppl 2)

3 Norris KC: Towards a new treatment paradigm for hyperphosphataemia in chronic renal disease. Dial Transplant 27:767-772, 1998

4 Pohlmeier R, Vienken J: Phosphate removal and hemodialysis conditions. Kiney Int Suppl 78:S190-S194, 2001

5 Slatopolsky E, Brown A, Dusso A: Role of phosphorus in the pathogenesis of secondary hyperparathyroidism. Am J Kidney Dis 37:S54-S57, 2001 (suppl 2)

6 Stamatakis MK, Pecora PG, Gunel E: Factors influencing adherence in chronic dialysis patients with hyperphosphataemia. J Ren Nutr 7:144-148, 1997

7 Prowant BF, Ryan LP, Satalowich RJ, et al: Effectiveness of a phosphorous educational program for dialysis patients. ANNA J 16:353-357, 1998

8 Schlatter S, Ferrans CE: Teaching program effects on high phosphorus levels in patients receiving haemodialysis. ANNA J 25:31-35, 1998

9 Ashurst IdB, Dobbie H: A randomised controlled trial of an educational intervention to improve phosphate levels in haemodialysis patients. J Ren Nutr 13:267-274, 2003.

10 Hecking E, Bragg-Gresham JL, Rayner HC, et al: Haemodialysis prescription, adherence and nutritional indicators in five European countries: Results from the dialysis outcomes and practice patterns study (DOPPS). Nephrol Dial Transplant 19:100-107, 2004

11 Department of Health: Patient group directions. Health Service Circular 2000/026. Available at: http://www.dh.gov.uk/PublicationsAndStatistics/LettersAndCirculars/HealthServiceCircu 
$\underline{\text { lars/HealthServiceCircularsArticle/fs/en?CONTENT_ID=4004179\&chk=Kncufs, }}$ accessed 8 April 2006

12 Bingham SA: The dietary assessment of individuals: Methods, accuracy, new techniques and recommendations. Nutr Abstr Rev 57:705-742, 1987

13 Smith AF, Beckett GJ, Walker SW, et al: Lecture notes on clinical biochemistry, 6th ed. Oxford, Blackwell Science, 1998

14 Thomas L: Calcium in Thomas L, ed Clinical laboratory diagnostics, in Thomas L (ed): Use and assessment of clinical laboratory results. Frankfurt / Main, TH-Books Verlagsgesellschaft, 1998, pp 231-241

15 Godber IM, Parker CR, Lawson N, et al: Comparison of intact and 'whole molecule' parathyroid hormone assays in patients with histologically confirmed post-renal transplant osteodystrophy. Ann Clin Biochem 39:314-317, 2002

16 Roberts NB, Clough A, Bellia JP, et al: Increased absorption of aluminium from a normal dietary intake in dementia. J Inorganic Biochem 69:171-176, 1998

17 Daugirdas JT: Second generation logarithmic estimates of single-pool variable volume Kt/V: an analysis of error. J Am Soc Nephrol 4:1205-1213, 1993

18 National Kidney Foundation: Clinical practice guidelines for bone metabolism and disease in chronic kidney disease. Am J Kidney Dis 42:S1-S201, 2003 (suppl 3)

19 Cupisti A, D’Alessandra C, Baldi R et al: Dietary habits and counselling focused on phosphate intake in hemodialysis patients with hyperphosphatemia. J Ren Nutr 14:220225,2004

20 Ford JC, Pope JF, Hunt AE et al: The effect of diet education on the laboratory values and knowledge of hemodialysis patients with hyperphosphatemia. J Ren Nutr 14:36-44, 2004

21 Ritzerfeld M, Klasser M, Mann H: Alfacalcidol in the therapy of renal bone disease. Int J Clin Pharmacol Ther 39:546-550, 2001 
22 McIntyre CW, Patel V, Taylor GS et al: A prospective study of combination therapy for hyperphosphataemia with calcium-containing phosphate binders and sevelamer in hypercalcaemic haemodialysis patients. Nephrol Dial Transplant 17:1643-1648, 2002

23 Craven C, Moreschi J: A dietitian-driven protocol for the management of renal bone disease in hemodialysis patients. J Ren Nutr 6:105-109, 1996

24 Ruffino M, de Bonis E, Martin M et al: Is it possible to control hyperphosphataemia with diet without inducing protein malnutrition. Nephrol Dial Transplant 13:65-67, 1998 (suppl 3)

25 Pifer TB, McCullough KP, Port FK et al: Mortality risk in hemodialysis patients and changes in nutritional indicators: DOPPS. Kidney Int 62:2238-2245, 2002

26 Braun J, Asmus HG, Holzer $\mathrm{H}$ et al: Long-term comparison of a calcium-free phosphate binder and calcium carbonate - phosphate metabolism and cardiovascular calcification. Clin Nephrol 62:104-115, 2004

27 Block GA, Spiegel DM, Ehrlich J et al: Effects of sevelamer and calcium on coronary artery calcification in patients new to hemodialysis. Kidney Int 68:1815-1824, 2005

28 Alfrey AC, Legendre GR, Kaehny WD: The dialysis encephalopathy syndrome: Possible aluminium intoxication. N Engl J Med 294:184-188, 1976

29 Pierides AM, Edwards WG, Cullum UX et al: Hemodialysis encephalopathy with osteomalacia fractures and muscle weakness. Kidney Int 18:115-125, 1980

30 Slatopolsky EA, Burke SK, Dillon MA et al: RenaGel, a nonabsorbed calcium- and aluminium-free phosphate binder, lowers serum phosphate and parathyroid hormone. Kidney Int 55:299-307, 1999

31 Sturtevant JM, Hawley CM, Reiger K et al: Efficacy and side-effect profile of sevelamer hydrochloride used in combination with conventional phosphate binders. Nephrology (Carlton) 9:406-413, 2004 
32 Coladonato JA: Control of hyperphosphatemia among patients with ESRD. J Am Soc Nephrol 16:S107-S114, 2005 


\section{Table 1}

Demographic, clinical and nutritional characteristics of the 34 randomised patients at recruitment.

Values are expressed as mean \pm SD except where indicated

\begin{tabular}{|c|c|c|c|}
\hline & $\begin{array}{c}\text { Phosphate } \\
\text { management protocol } \\
\text { group } \\
(\mathrm{n}=17)\end{array}$ & $\begin{array}{c}\text { Standard practice } \\
\text { group } \\
(\mathrm{n}=17)\end{array}$ & $\mathrm{P}$ value \\
\hline Age (years) & $51.1 \pm 12.7$ & $47.6 \pm 14.4$ & 0.46 \\
\hline Male : female ratio $(\mathrm{n})$ & $11 \mathrm{M}: 6 \mathrm{~F}$ & $12 \mathrm{M}: 5 \mathrm{~F}$ & 0.71 \\
\hline \multicolumn{4}{|l|}{ Race (n) } \\
\hline Black & 5 & 4 & \\
\hline Indoasian & 1 & 2 & \\
\hline White & 11 & 10 & \\
\hline Other & 0 & 1 & \\
\hline \multicolumn{4}{|l|}{ Aetiology (n) } \\
\hline Glomerulonephritis & 5 & 2 & \\
\hline Diabetes & 3 & 2 & \\
\hline Hypertension & 2 & 3 & \\
\hline Adult polycystic kidneys & 1 & 2 & \\
\hline Pyelonephritis & 0 & 2 & \\
\hline Unknown & 2 & 2 & \\
\hline Other $^{\mathrm{a}}$ & 4 & 4 & \\
\hline $\begin{array}{l}\text { Length of time on } \\
\text { haemodialysis (years) }\end{array}$ & $2.0(<1-10)$ & $2.5(<1-7)$ & 0.5 \\
\hline \multicolumn{4}{|l|}{ Nutrition } \\
\hline Height (m) & $1.71 \pm 0.10$ & $1.66 \pm 0.10$ & 0.13 \\
\hline Weight (kg) & $71.1 \pm 15.8$ & $71.7 \pm 13.1$ & 0.90 \\
\hline $\operatorname{BMI}\left(\mathrm{kg} / \mathrm{m}^{-2}\right)$ & $24.3 \pm 4.8$ & $26.3 \pm 5.5$ & 0.27 \\
\hline
\end{tabular}

${ }^{a}$ Include focal segmental glomerulosclerosis, IgA nephropathy, oxalosis, tuberculosis, Goodpasture's syndrome 


\section{Table 2}

Effect of phosphate management protocol and standard practice on biochemical variables in patients undergoing regular haemodialysis (mean \pm 1 SD except where stated).

\begin{tabular}{|c|c|c|c|c|c|c|c|c|c|c|}
\hline & \multicolumn{4}{|c|}{ Phosphate management protocol $(n=14)$} & \multicolumn{4}{|c|}{ Standard practice $(n=17)$} & \multirow{2}{*}{$\begin{array}{c}\text { Intergroup } \\
\text { P value }\end{array}$} & \multirow{2}{*}{$\begin{array}{c}\text { Intergroup } \\
\text { P value }\end{array}$} \\
\hline & Before & After & Change & Intragroup & Before & After & Change & Intragroup & & \\
\hline & & & & $\mathrm{P}$ value & & & & $\mathrm{P}$ value & Before & Change \\
\hline $\begin{array}{l}\text { Serum phosphate } \\
(\mathrm{mmol} / \mathrm{l})\end{array}$ & $2.03 \pm 0.28$ & $1.81 \pm 0.54$ & $-0.22 \pm 0.67$ & 0.24 & $1.88 \pm 0.32$ & $2.07 \pm 0.25$ & $+0.19 \pm 0.32$ & 0.03 & 0.18 & 0.03 \\
\hline $\begin{array}{l}\text { Corrected calcium } \\
(\mathrm{mmol} / \mathrm{l})\end{array}$ & $2.48 \pm 0.26$ & $2.47 \pm 0.15$ & $-0.01 \pm 0.28$ & 0.95 & $2.34 \pm 0.26$ & $2.34 \pm 0.26$ & $0 \pm 0.16$ & 0.92 & 0.15 & 0.91 \\
\hline $\begin{array}{l}\mathrm{Ca} \times \mathrm{P} \\
\left(\mathrm{mmol}^{2} / \mathrm{l}^{2}\right)\end{array}$ & $5.01 \pm 0.74$ & $4.43 \pm 1.20$ & $-0.58 \pm 1.62$ & 0.20 & $4.38 \pm 0.86$ & $4.80 \pm 0.51$ & $+0.41 \pm 0.81$ & 0.05 & 0.04 & 0.04 \\
\hline $\begin{array}{l}\mathrm{iPTH}^{\mathrm{a}} \\
(\mathrm{pmol} / \mathrm{l})\end{array}$ & $\begin{array}{c}36 \\
(0.3-224)\end{array}$ & $\begin{array}{c}51 \\
(0.3-175)\end{array}$ & $\begin{array}{c}-2 \\
(-75 \text { to }+40)\end{array}$ & 0.38 & $\begin{array}{c}29 \\
(0.3-237)\end{array}$ & $\begin{array}{c}21 \\
(0.3-165)\end{array}$ & $\begin{array}{c}0 \\
(-214 \text { to }+26)\end{array}$ & 0.64 & 0.85 & 0.89 \\
\hline
\end{tabular}

${ }^{\mathrm{a}}$ median (range) 


\section{Table 3}

Effect of phosphate management protocol and standard practice on patients achieving individual K/DOQI targets ${ }^{18}$

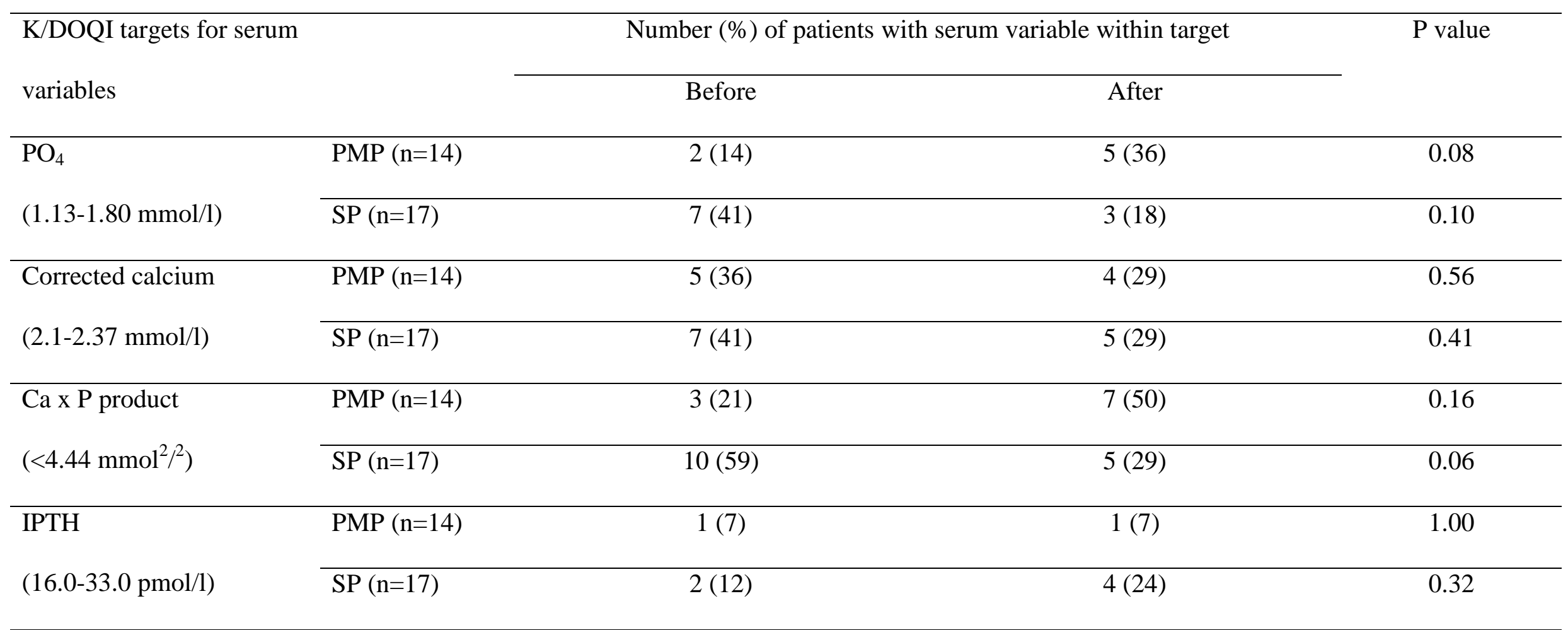

Comparisons undertaken using a McNemar test 


\section{Table 4}

Effect of phosphate management protocol and standard practice on patients achieving multiple K/DOQI targets ${ }^{18}$

\begin{tabular}{|c|c|c|c|c|c|c|c|}
\hline & \multicolumn{6}{|c|}{ Number (\%) of patients achieving K/DOQI } & $\mathrm{P}$ value \\
\hline $\begin{array}{l}\text { Phosphate management } \\
\text { protocol }(n=14)\end{array}$ & After & $3(21)$ & $6(43)$ & $4(29)$ & $1(7)$ & 0 & 0.18 \\
\hline Standard practice $(\mathrm{n}=17)$ & After & $5(30)$ & $7(41)$ & $5(29)$ & 0 & 0 & 0.10 \\
\hline
\end{tabular}

Comparisons undertaken using a Cochran test for linear trend 


\section{Figure 1}

Phosphate management protocol algorithms

\begin{tabular}{|c|c|c|}
\hline 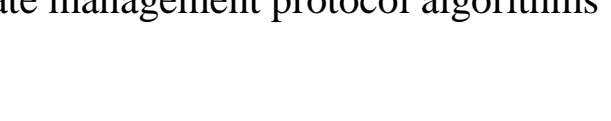 & $\begin{array}{c}\text { Serum phosphate increased } \\
(>1.8 \mathrm{mmol} / \mathrm{l})\end{array}$ & \\
\hline $\begin{array}{l}\text { Corrected calcium } \downarrow \\
(<2.2 \mathrm{mmol} / \mathrm{l})^{*}\end{array}$ & $\begin{array}{l}\text { Corrected calcium in normal range } \\
(2.1-2.75 \mathrm{mmol} / \mathrm{l})^{*}\end{array}$ & Corrected calcium $\uparrow$ \\
\hline Start $/ \uparrow$ dose calcium-containing & Start $/ \uparrow$ dose phosphate binder. & Stop/ $\downarrow$ dose calcium-containing \\
\hline $\begin{array}{l}\text { phosphate binder } \\
\text { PTH }<10 \text { pmol/1 (unlikely scenario) } \\
\text { Stop/ } \downarrow \text { dose alfacalcidol }\end{array}$ & $\begin{array}{l}\text { If corrected calcium is consistently at the } \\
\text { upper end of the normal range, consider } \\
\text { switch to non-calcium phosphate binder } \\
\text { (aluminium or sevelamer) }\end{array}$ & $\begin{array}{l}\text { Start } / \uparrow \text { dose non-calcium phosphate } \\
\text { binder (aluminium or sevelamer) }\end{array}$ \\
\hline PTH 10-20pmol/1 & PTH $10-20 \mathrm{pmol} / 1$ & $\begin{array}{l}\text { Stop alfacalcidol if: } \\
\text { EITHER }\end{array}$ \\
\hline Start/ maintain dose alfacalcidol & Maintain dose alfacalcidol & $\begin{array}{l}\text { Corrected Calcium }>3.0 \mathrm{mmol} / 1 \\
\text { OR }\end{array}$ \\
\hline$\underline{\mathrm{PTH}}>20 \mathrm{pmol} / 1$ & $\underline{\mathrm{PTH}}>20 \mathrm{pmol} / 1$ & Persistent Corrected Calcium \\
\hline $\begin{array}{l}\text { Start/ } \uparrow \text { dose alfacalcidol (only after } \\
\text { achieving phosphate level in target } \\
\text { range) }\end{array}$ & $\begin{array}{l}\text { Start } / \uparrow \text { dose alfacalcidol (only after } \\
\text { achieving phosphate level in target range) }\end{array}$ & $\begin{array}{l}>2.7 \mathrm{mmol} / \mathrm{l} \text { after reduction of dose of } \\
\text { calcium-containing phosphate binder }\end{array}$ \\
\hline $\begin{array}{ll}\text { Refer } \\
\text { - } & \text { PTH }<10 \mathrm{pmol} / 1 \\
\text { - } & \text { PTH }>100 \mathrm{pmol} / 1 \text { consistently } \\
\text { - } & \text { Corrected Calcium }<2 \mathrm{mmol} / 1 \\
\text { - } & \text { If max dose alfacalcidol reached } \\
\text { - } & \text { High aluminium level }\end{array}$ & \begin{tabular}{ll}
\multicolumn{2}{l}{ Refer } \\
$\qquad$ & PTH $<10 \mathrm{pmol} / 1$ \\
- & PTH $>100 \mathrm{pmol} / 1$ consistently \\
- & If max dose alfacalcidol reached \\
- & High aluminium level
\end{tabular} & 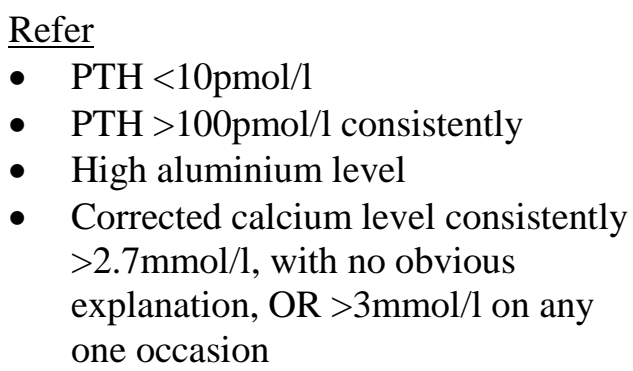 \\
\hline
\end{tabular}




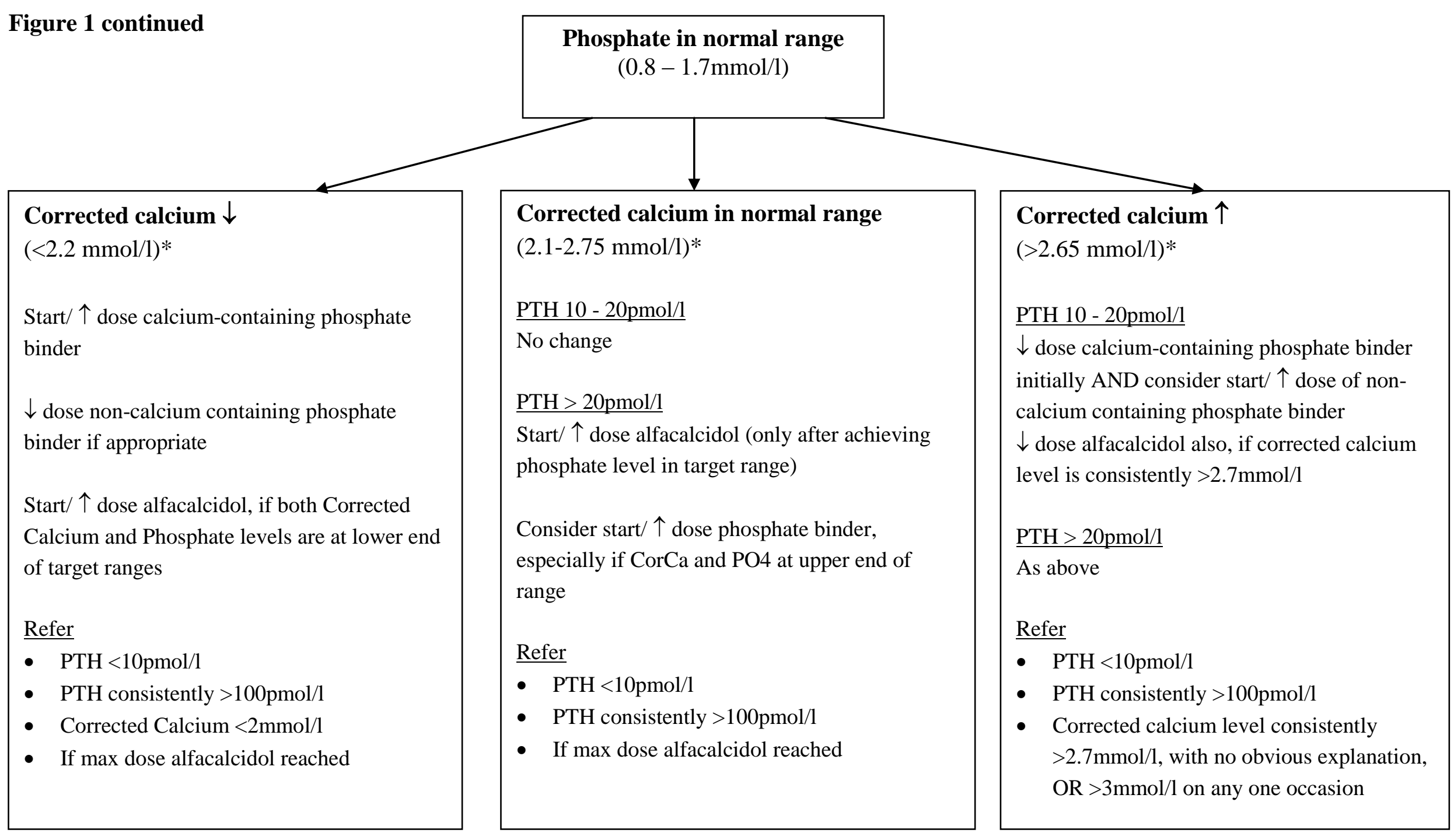

*There is a small overlap in the threshold corrected calcium levels of the three treatment pathways so that patients whose levels fluctuate around these values do not have their medication adjusted at every review 


\section{Figure 2}

Flow of participants through trial

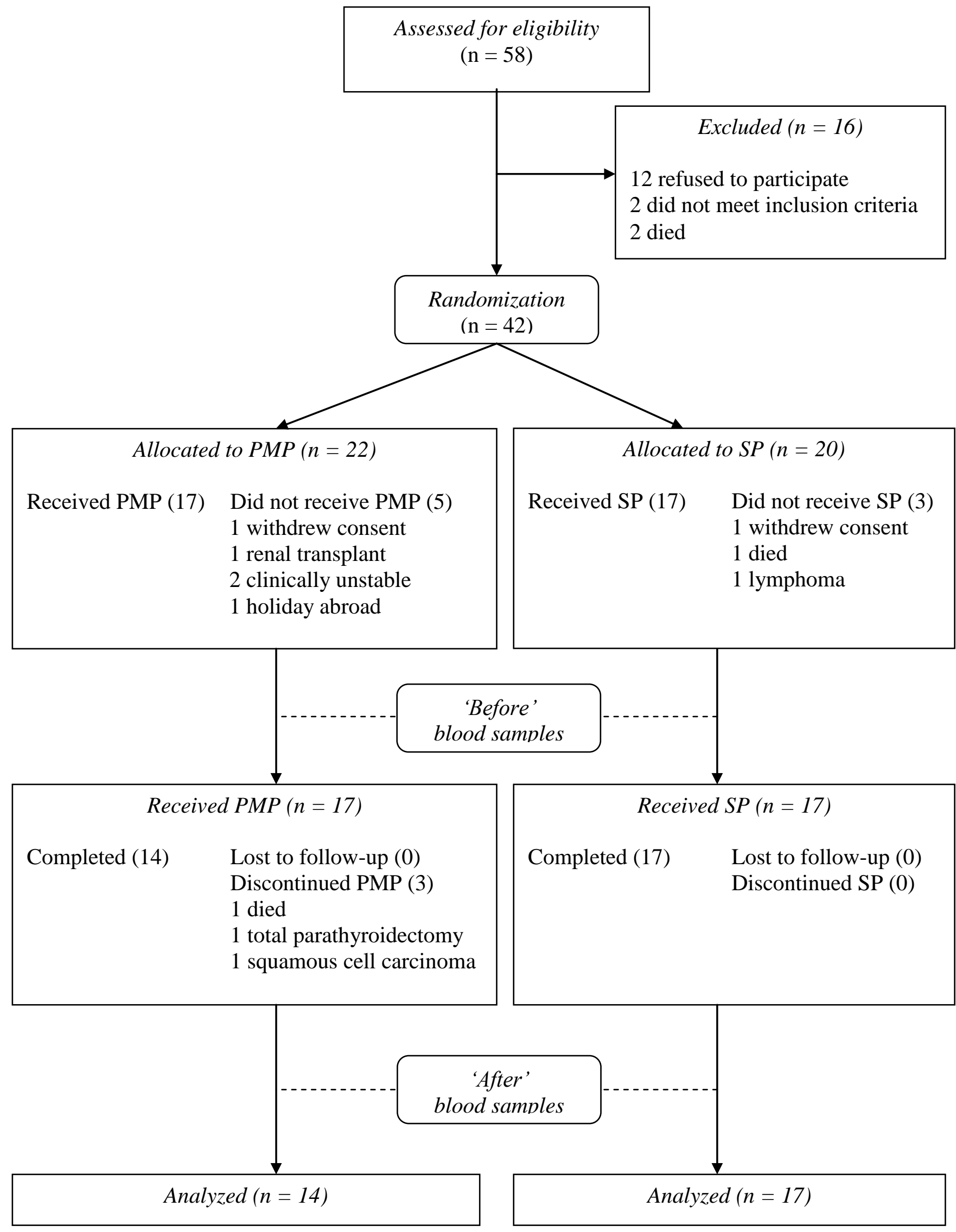

